\title{
Preparation of zirconia-modified epoxy acrylate emulsion and its application in waterborne anticorrosion coating
}

\author{
Shaoxiang Li $^{1,2,3}$, Xin Zhang ${ }^{1,2,3}$, Wenjuan $Q u^{1,2,3, *}$, Lijie Wang ${ }^{1,2,3}$, Houwei Li ${ }^{1,2,3}$, Jiaxin Liu $^{1,2,3}$ \\ ${ }^{1}$ College of Environment and Safety Engineering, Qingdao University of Science and Technology, \\ Qingdao, 266042, P. R. China \\ ${ }^{2}$ Shandong Engineering Research Center for Marine Environment Corrosion and Safety Protection, \\ Qingdao University of Science and Technology, Qingdao, 266042, P. R. China \\ ${ }^{3}$ Shandong Engineering Technology Research Center for Advanced Coating, Qingdao University of \\ Science and Technology, Qingdao, 266042, P. R. China \\ *E-mail: qwj710@163.com
}

Received: 15 September 2021 / Accepted: 4 October 2021 / Published: 6 December 2021

\begin{abstract}
Zirconia-modified epoxy acrylate emulsion was synthesized via soap-free emulsion polymerization by adding different amounts of modified $\mathrm{ZrO}_{2}$ nanoparticles. The modified $\mathrm{ZrO}_{2}$ nanoparticles were characterized by Fourier transform infrared spectroscopy (FTIR), X-ray diffraction spectroscopy (XRD) and scanning electron microscopy (SEM). Thermogravimetric analysis (TGA) indicated that the addition of modified $\mathrm{ZrO}_{2}$ could improve the thermal stability of the films formed by the emulsions. Moreover, the electrochemical impedance spectra (EIS) results showed that the film former of zirconia-modified epoxy acrylate emulsion could effectively improve the corrosion resistance of the coatings. The results showed that the emulsion containing $1 \%$ modified $\mathrm{ZrO}_{2}$ had the best thermal stability and the corresponding coating had the best corrosion resistance.
\end{abstract}

Keywords: Epoxy coatings; Zirconia; Nanoparticles; Corrosion

\section{$\underline{\text { FULL TEXT }}$}

(C) 2022 The Authors. Published by ESG (www.electrochemsci.org). This article is an open access article distributed under the terms and conditions of the Creative Commons Attribution license (http://creativecommons.org/licenses/by/4.0/). 